\title{
Local Structure and Ionic Conduction at Interfaces of Electrode and Solid Electrolytes
}

\author{
Hirotsohi Yamada, ${ }^{a, *, z}$ Yusuke Oga, ${ }^{\text {b }}$ Isamu Saruwatari, ${ }^{\mathrm{b}}$ and Isamu Moriguchi ${ }^{\mathrm{a}}$ \\ ${ }^{a}$ Graduate School of Engineering and ${ }^{b}$ Graduate School of Science and Technology, Nagasaki University, Nagasaki \\ 8528521, Japan
}

\begin{abstract}
All solid state batteries are attracting interests as next generation energy storage devices. However, little is known on interfaces between active materials and solid electrolytes, which may affect performance of the devices. In this study, interfacial phenomena between electrodes and solid electrolytes of all solid state batteries were investigated by using nano-composites of $\mathrm{Li}_{2} \mathrm{SiO}_{3}-\mathrm{TiO}_{2}$, $\mathrm{Li}_{2} \mathrm{SiO}_{3}-\mathrm{LiTiO}_{2}$, and $\mathrm{Li}_{2} \mathrm{SiO}_{3}-\mathrm{FePO}_{4}$. Studies on ionic conductivity of these composites revealed lithium ion transfer across the interfaces without electric field, which depended on electrode potentials. For $\mathrm{Li}_{2} \mathrm{SiO}_{3}-\mathrm{TiO}_{2}$, conductivity of the composites was enhanced by addition of $\mathrm{TiO}_{2}$ and well explained by space charge layer model. With $\mathrm{LiTiO}_{2}$ which shows lower electrode potential, the conductivity was deteriorated due to decrease in vacancies in $\mathrm{Li}_{2} \mathrm{SiO}_{3}$. At the interface of $\mathrm{Li}_{2} \mathrm{SiO}_{3}-\mathrm{FePO}_{4}$, a lot of $\mathrm{Li}_{\text {ions in }}$ $\mathrm{Li}_{2} \mathrm{SiO}_{3}$ are trapped at the interface or maybe are inserted into $\mathrm{FePO}_{4}$, resulting in many vacancies in $\mathrm{Li}_{2} \mathrm{SiO}_{3}$ and lattice distortion. The results show the ionic conduction at the interface is strongly affected by the electrode potential and the importance of design of interfaces of all solid state batteries is pointed out.
\end{abstract}

(C) 2012 The Electrochemical Society. [DOI: 10.1149/2.035204jes] All rights reserved.

Manuscript submitted September 30, 2011; revised manuscript received December 16, 2011. Published January 24, 2012.

Lithium ion batteries (LIBs) are widely used as rechargeable batteries for portable electronic devices due to their large energy densities among currently available energy storage devices. The development of LIBs is now toward an application to large-scaled devices, such as electric vehicles and load leveling of renewable energies. ${ }^{1-6}$ In this context, all solid state batteries employing inorganic solid electrolytes are attracting many interests because non-flammability and non-volatility of inorganic solid electrolytes enhances safety and reliability of batteries, which may be of importance for large-scaled devices. $^{7-9}$ In addition, metallic lithium may be used as negative electrodes of all solid state batteries because the dense solid electrolytes protect unfavorable dendritic lithium deposition on negative electrodes, which can happens for conventional LIBs with liquid electrolytes. ${ }^{10}$ Although poor lithium ionic conductivity of solid electrolytes have been mentioned as a drawback of all solid state batteries, several solid electrolytes with ionic conductivities higher than $10^{-4} \mathrm{~S} \mathrm{~cm}{ }^{-1}$ have been developed. ${ }^{11-16}$ Recently, very high $\mathrm{Li}^{+}$ conductivity of $10^{-2} \mathrm{~S} \mathrm{~cm}^{-1}$ at room temperature is reported for $\mathrm{Li}_{10} \mathrm{GeP}_{2} \mathrm{~S}_{12},{ }^{17}$ and the problem on the poor conductivity seems to be rather improved. The other point to be taken into consideration for practical use of all solid state batteries would be the interface resistance between electrolytes and electrodes. The solid electrolytes don't show fluidity and thus it is difficult to prepare good contact at interfaces where electrochemical reactions take place. What is more, recently, interfacial resistance due to the other reasons has been reported by several researchers, which could be reduced by preparing buffer layers at the interface. ${ }^{18-22}$ There have been three models proposed as the origin of the interfacial resistance. The first proposed mechanism is the formation of space charge layer at the interface inside the solid electrolytes in which lithium ion concentration is reduced and the ionic conductivity of the solid electrolytes is decreased. ${ }^{18,19}$ The second model is that the interfacial chemical reaction between electrodes and solid electrolytes cause the interfacial resistance. ${ }^{20,21}$ The last mechanism is the lattice mismatch at the interface which may be applied for thin film systems. ${ }^{22}$ Mathematical calculation of interfaces has also been tried, ${ }^{23}$ but it requires a precise and proper model that includes all interfacial physical and chemical phenomena. However, details of the interfacial phenomena between solid electrolytes and electrodes are not known. For example, according to a very recent work using in-situ electron holography, potential drop in a solid electrolyte ranges for about $1 \mu \mathrm{m}$, which cannot be explained by the conventional space charge layer model with the Gouy-Chapman type

\footnotetext{
* Electrochemical Society Active Member.

${ }^{z}$ E-mail: h-yama@nagasaki-u.ac.jp
}

defects profile. ${ }^{24}$ While the fundamental model has been established for liquid electrolyte systems, only a few things have been revealed for solid electrolyte systems due to difficulty in analysis of local structure and/or conductivity of solid-solid interfaces that would be typically several nanometer in size.

In this study, we attempt to clear fundamental phenomena at the interfaces between solid electrolytes and electrodes by fabricating nano-composites consisting of nano-sized solid electrolytes and nanosized active materials. In these composites, large interfacial area would be obtained and most of materials are affected by the interfaces. For these nano-composites, conventional macroscopic techniques can be used to analyze local microscopic phenomena at the interfaces. ${ }^{25,26}$ In this report, $\mathrm{Li}_{2} \mathrm{SiO}_{3}$ (LSO) was used as a solid electrolyte and three active materials with different electrode potentials were mixed with nano LSO: anatase $\mathrm{TiO}_{2}$ (TO; open circuit potential $(\mathrm{OCP}) \sim 3.3 \mathrm{~V}$ vs. $\left.\mathrm{Li} / \mathrm{Li}^{+}\right)$, lithium doped $\mathrm{TiO}_{2}\left(\mathrm{Li}_{0.01} \mathrm{TiO}_{2}\right.$ (LTO); OCP $2.7 \mathrm{~V}$ vs. $\mathrm{Li} / \mathrm{Li}^{+}$) and $\mathrm{FePO}_{4}\left(\mathrm{FPO}\right.$; OCP $\sim 3.5 \mathrm{~V}$ vs. $\left.\mathrm{Li} / \mathrm{Li}^{+}\right)$. LSO is not a so common solid electrolyte because of its poor lithium ion conductivity, but may be useful because of its chemical stability and electrochemical stability. The nano-composites were fabricated by mechanical mixing of nanoparticles.

\section{Experimental}

Nano LSO was prepared from commercial $\mathrm{Li}_{2} \mathrm{SiO}_{3}$ powder (> 99.5\%, Kishida Chemical Co., Ltd., Japan) by using a planetary ball-mill P-6 (Fritsch GmbH, Germany) at $300 \mathrm{rpm}$ for 36 hours in ethanol with a $\mathrm{ZrO}_{2}$ pot and $\mathrm{ZrO}_{2}$ balls $(3 \mathrm{~mm}$ in a diameter). After milled, the powder was dried and annealed in $\mathrm{N}_{2}$ at $200^{\circ} \mathrm{C}$ to remove adsorbed water and ethanol. $\mathrm{Nano} \mathrm{TiO}_{2}$ (anatase-type) was supplied as a reference catalyst JRC-TiO-1 by Catalysis Society of Japan. Nano $\mathrm{LiTiO}_{2}$ was obtained by chemical lithium insertion to nano $\mathrm{TiO}_{2}$ by using a hexane solution of $n$-butyllithium (Wako Pure Chemical Industries, Ltd., Japan), which was diluted to $0.016 \mathrm{M}$ with hexane. Nano $\mathrm{FePO}_{4}$ was synthesized in the following three steps: first, $\mathrm{LiFePO}_{4}$ (LFP) was prepared by solid state reaction at $700^{\circ} \mathrm{C}$ for 16 hours from a mixture of $\mathrm{LiNO}_{3}, \mathrm{Fe}\left(\mathrm{NO}_{3}\right)_{3} \cdot 9 \mathrm{H}_{2} \mathrm{O}$, and $\mathrm{NH}_{4} \mathrm{H}_{2} \mathrm{PO}_{4}$ with a mole ratio of $1: 1: 1$. Then, the LFP powder was mechanically milled in ethanol by using a planetary ball-mill to obtain nano LFP particles. Finally, the nano LFP was oxidized in an acetonitrile solution of $\mathrm{NO}_{2} \mathrm{BF}_{4}\left(>95 \%\right.$, Aldrich) and dried to obtain nano FPO. ${ }^{27}$ These nano-particles of active materials were preheated in $\mathrm{N}_{2}$ at $200^{\circ} \mathrm{C}$ to remove adsorbed water, and then the nano-composites were prepared by mechanical milling of the mixture of nano LSO and nano-sized active materials (TO, LTO and FPO) at $150 \mathrm{rpm}$ for 2 hours in dry Ar. 

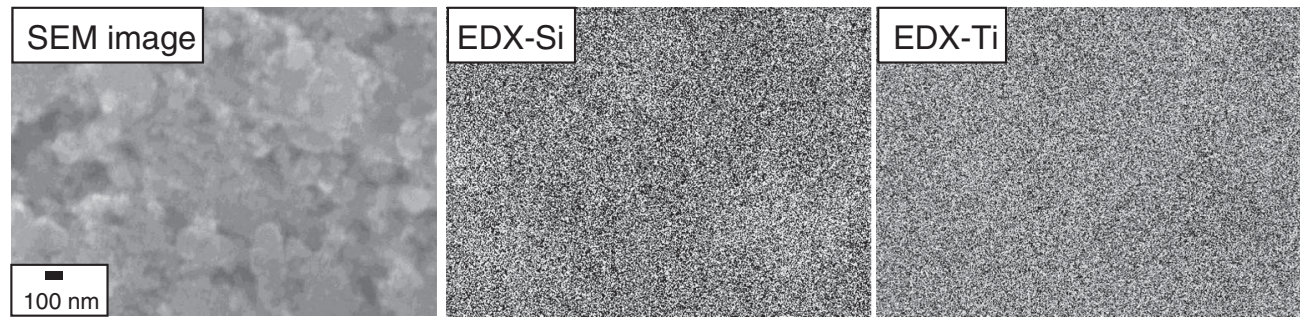

Figure 1. FE-SEM and EDX images of the nanocomposite of LSO-TO with a volume fraction of $\mathrm{TiO}_{2}$ of 0.4 .

OCP of all active materials was confirmed by using three-electrode cells. A working electrode of a cell was a mixture of nano-sized active materials, acetylene black (kindly supplied from Denki Kagaku Kogyo, Japan) and poly(tetrafluoroethylene). A reference and a counter electrode were lithium foil, and a $1 \mathrm{M}$ solution of $\mathrm{LiClO}_{4}$ in mixed solvent of propylene carbonate and 1,2-dimethoxyethane was employed as an electrolyte. All the synthesis procedure was carried out in a dry $\mathrm{N}_{2}$ or Ar atmosphere to avoid adsorption of water that may cause side reactions.

The particle sizes and dispersion of the nano particles and nanocomposites were analyzed by field-emission scanning electron microscopy (FE-SEM) equipped with energy dispersive X-ray (EDX) spectrometer (JSM-7500FAM; JEOL Ltd., Japan) and $\mathrm{N}_{2}$ sorption at 77 K (BELSORP-mini II, BEL Japan Inc., Japan). The crystal structure was investigated by X-ray diffraction (XRD) on a RINT-2200 (Rigaku Corporation, Japan). Local structure of lithium ions was analyzed by ${ }^{7} \mathrm{Li}$ magic angle spinning nuclear magnetic resonance (MAS-NMR) spectra that were recorded on a JNM-ECA 400 (JEOL Ltd., Japan).

For the conductivity measurements, the specimens were uniaxially pressed at $10 \mathrm{MPa}$ into disks $(7 \mathrm{~mm}$ in diameter and $0.5 \sim 0.7 \mathrm{~mm}$ in thickness) and gold or platinum electrodes were attached on both sides of the disks by sputtering. Porosity of the disks was obtained by comparing geometrical density and calculated density using lattice parameters, and was 35(3)\%, which was independent of specimens. The conductivity of the specimens was measured by an ac impedance method and by a dc polarization technique in a temperature range of $200 \sim 350^{\circ} \mathrm{C}$. The ac impedance measurements were conducted on a frequency response analyzer S1260 (Solartron analytical, U.K.) with an oscillation voltage of $0.1 \mathrm{~V}$ for a frequency range from $1 \mathrm{MHz}$ to $0.1 \mathrm{~Hz}$. The dc polarization was measured by a potentiogalvanostat S1287 (Solartron analytical). From ac impedance spectra, total conductivity of ion $\left(\mathrm{Li}^{+}\right.$in this case, $\left.\sigma_{\mathrm{Li}+}\right)$ and electron $\left(\sigma_{\mathrm{e}}\right)$ are obtained. For ionic conductors, i.e. $\sigma_{\mathrm{Li}+} \gg \sigma_{\mathrm{e}}$, a Nyquist plot $\left(Z^{\prime \prime}\right.$ vs. $Z^{\prime \prime}$ ) of an ac impedance of a sample shows one or two depressed semi-circle(s) for a higher frequency range, while a straight line (typically slightly inclined) appeared at a lower frequency range. In this case, $\sigma_{\mathrm{Li}+}$ was estimated from a resistance that was obtained from the diameter of the semi-circle(s) on the Nyquist plot. For mixed conductors, where electronic conductivity is not negligible, the Nyquist plot converged at a point on the real axis with decreasing the frequency. In this case, the diameter of the semi-circle(s) gives the sum of $\sigma_{\mathrm{Li}+}$ and $\sigma_{e}$, and a dc measurement was conducted, which gives $\sigma_{e}$ for the ion blocking electrodes. Then, lithium ion conductivity of the specimen was estimated by subtracting $\sigma_{\mathrm{e}}$ from total conductivity $\left(\sigma_{\mathrm{Li}+}+\sigma_{\mathrm{e}}\right)$. All the measurements as well as handling and transfer were conducted in a dry Ar atmosphere.

\section{Results and Discussion}

Preparation of nano $\mathrm{Li}_{2} \mathrm{SiO}_{3}$. - Milling of commercial LSO resulted in reduction of particle size from $1 \sim 10 \mu \mathrm{m}$ to ca. $50 \mathrm{~nm}$, which was confirmed by FE-SEM. A BET specific surface area of nano LSO analyzed from the $\mathrm{N}_{2}$ sorption measurement were $21.9 \mathrm{~m}^{2} \mathrm{~g}^{-1}$ and a particle size of $54 \mathrm{~nm}$ was estimated by assuming monodispersed spherical particles, which agreed well with the result of the
SEM observation. With increasing a milling rotation rate or a milling time, the smaller particles were obtained, while $\mathrm{ZrO}_{2}$ and $\mathrm{Li}_{2} \mathrm{CO}_{3}$ as contaminants increased. From the particle sizes and the amount of contaminants, the milling condition ( $300 \mathrm{rpm}, 36$ hours) was decided, which resulted in 0.11 vol.\% of $\mathrm{ZrO}_{2}$ that would be negligible in this study.

$\mathrm{Li}_{2} \mathrm{SiO}_{3}-\mathrm{TiO}_{2}$ nano-composite. - For LSO-TO systems, nano TO with a diameter of $11 \mathrm{~nm}$ was used. The FE-SEM-EDX analysis showed a homogeneous dispersion of both nano LSO and nano TO in the nano-composite of LSO-TO as shown in Fig. 1. XRD patterns indicated no structural change occurred for both nano LSO and nano TO by the mixing process (Fig. 2). Figures $3 \mathrm{a}$ and $3 \mathrm{~b}$ show the Nyquist plot of nano LSO and LSO-TO $\left(\mathrm{TiO}_{2}: 40 \mathrm{vol} . \%\right)$, respectively, where a semi-circle and a straight line were observed for the both samples, meaning they were not mixed conductors but ionic conductors. Figure 4a demonstrates the ionic conductivity of nano LSO and LSOTO. As can be clearly seen, $\mathrm{Li}^{+}$conductivity increased by about one order of magnitude when nano TO was added to nano LSO. The composition dependence, which is shown in Fig. 4b, indicated the conductivity increased almost linearly with increasing the volume fraction $(\varphi)$ of nano $\mathrm{TO}$ for $\varphi \leq 0.4$, although $\mathrm{TiO}_{2}$ does not contain and conduct $\mathrm{Li}^{+}$. And at $\varphi=0.5$, the conductivity of the composite decreased. It should be noted that activation energies of $\mathrm{Li}^{+}$conduction of the composites are almost the same as that of the nano LSO. This means the conduction mechanism in the composites is the same as that in the nano LSO, i.e. migration of Li vacancy $\left(V_{\mathrm{Li}}{ }^{\prime}\right)$ The increase in the conductivity is accounted for by the increase in the density of the charge carrier $\left(V_{\mathrm{Li}}{ }^{\prime}\right)$. All of these phenomena are well explained by the space charge layer (SCL) model as shown in

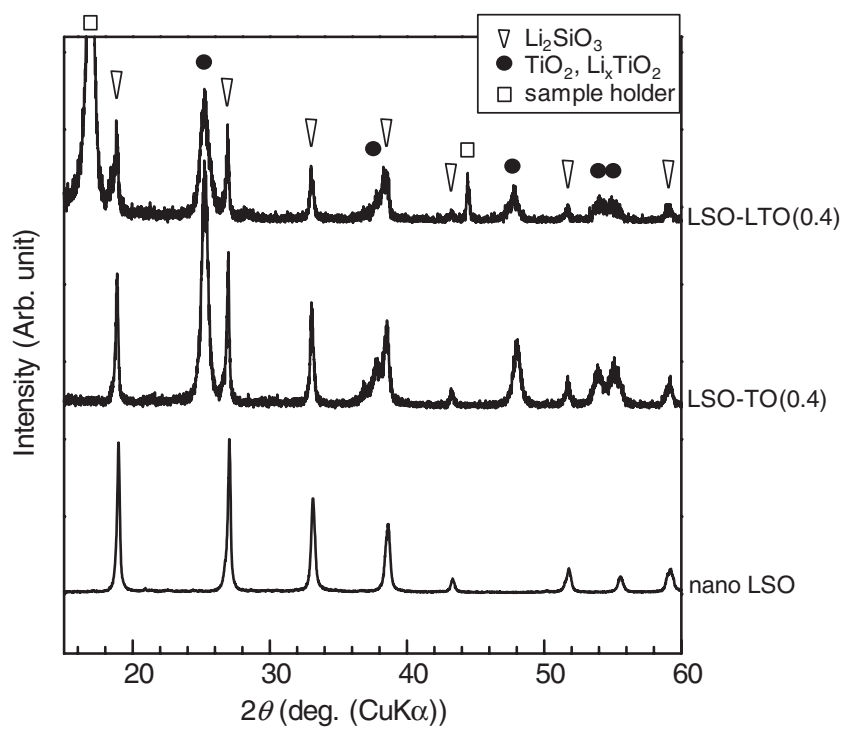

Figure 2. XRD profiles of nano LSO, nano-composites of LSO-TO and LSO-LTO 

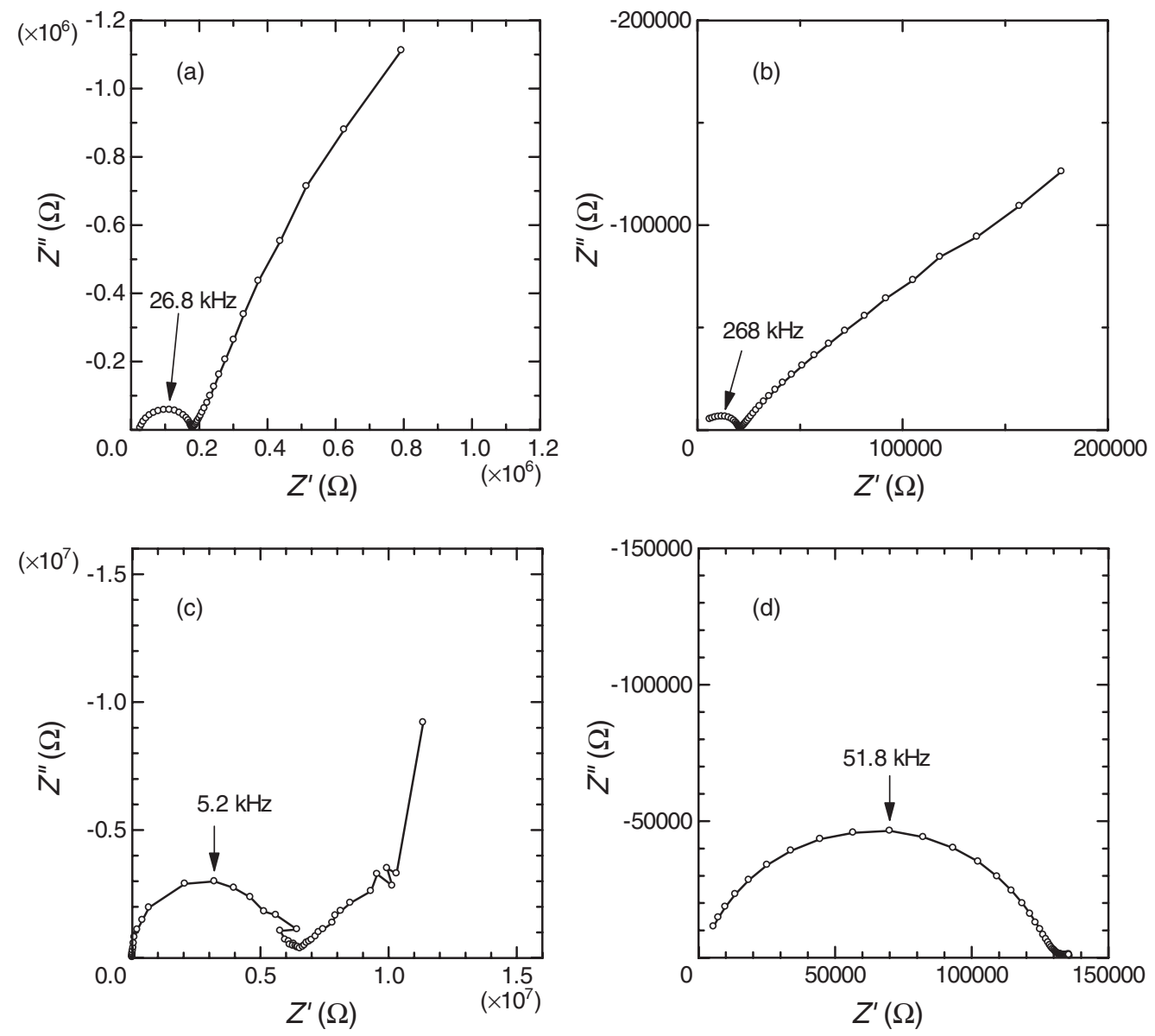

Figure 3. Nyquist plots of (a) nano LSO at $334^{\circ} \mathrm{C}$, (b) LSO-TO(0.4) at $338^{\circ} \mathrm{C}$

${ }^{\circ}$, (c) $\operatorname{LSO}-\mathrm{LTO}(0.4)$ at $339^{\circ} \mathrm{C}$, and (d) $\mathrm{LSO}-\mathrm{FPO}(0.4)$ at $343^{\circ} \mathrm{C}$.

Fig. 5b: $\mathrm{Li}^{+}$in LSO is attracted to the surface of $\mathrm{TiO}_{2}$ and $V_{\mathrm{Li}}{ }^{\prime}$ increases in the SCL of LSO to compensate the accumulated charge, resulting in the enhanced ionic conductivity. ${ }^{28}$ According to the SCL model with Gouy-Chapman type defects profile, ${ }^{29}$ the conductivity of the composites $\sigma_{\mathrm{m}}$ is given by

$$
\sigma_{\mathrm{m}}=(1-\varphi) \sigma_{\infty}+\beta_{\mathrm{L}} \varphi \Omega_{\mathrm{A}} \sqrt{2 \varepsilon_{\mathrm{r}} \varepsilon_{0} R T c_{0}} u_{\mathrm{v}}
$$

where $\varphi$ is the volume fraction of the second phase $\left(\mathrm{TiO}_{2}\right.$, in this case), $\sigma_{\infty}$ the conductivity in bulk; $\beta_{\mathrm{L}}$ is a factor that represents degree of percolation, $\Omega_{\mathrm{A}}$ the ratio of surface to volume of insulator phase, $\varepsilon_{\mathrm{r}}$ the relative permittivity of ionic conductor, $\varepsilon_{0}$ the permittivity of vacuum, and $u_{\mathrm{v}}$ the mobility of vacancy; $R$ is the gas constant, $T$ the temperature, and $c_{0}$ the concentration of vacancies immediately adjacent to the insulator's surface. According to Eq. 1, the conductivity decrease for higher $\mathrm{TiO}_{2}$ composition is explained by the increase in the insulating phase. The SCL is almost twice as thick as the Debye length $\lambda$ :

$$
\lambda=\sqrt{\frac{\varepsilon_{\mathrm{r}} \varepsilon_{0} R T}{2 z^{2} F^{2} c_{\infty}}}
$$

where $F$ is the Faraday constant and $c_{\infty}$ is the concentration of vacancies in bulk. For LSO, $\lambda$ is calculated to be about $2 \mathrm{~nm}$ at $500 \mathrm{~K}$.

Let us discuss the driving force of the $\mathrm{Li}^{+}$attraction by $\mathrm{TiO}_{2}$. From the thermodynamic point of view, it is supposed that $\mathrm{Li}^{+}$is more stable in or on $\mathrm{TiO}_{2}$ than in $\mathrm{Li}_{2} \mathrm{SiO}_{3}$. When two materials are in contact with each other and small amounts of $\mathrm{Li}^{+}$transfer from material $1\left(\mathrm{Li}_{x} \mathrm{M}_{1}\right)$ to material $2\left(\mathrm{Li}_{y} \mathrm{M}_{2}\right)$, the reaction equation and the change in the
Gibbs' free energy are given by

$$
\mathrm{Li}_{x} \mathrm{M}_{1}+\mathrm{Li}_{y} \mathrm{M}_{2} \rightarrow \mathrm{Li}_{x-\Delta x} \mathrm{M}_{1}+\mathrm{Li}_{y+\Delta x} \mathrm{M}_{2}
$$

$$
\Delta G=\left\{G\left(\mathrm{Li}_{x-\Delta x} \mathrm{M}_{1}\right)-G\left(\mathrm{Li}_{x} \mathrm{M}_{1}\right)\right\}+\left\{G\left(\mathrm{Li}_{y+\Delta x} \mathrm{M}_{2}\right)-G\left(\mathrm{Li}_{y} \mathrm{M}_{2}\right)\right\}
$$

It should be noted that the second term of the right hand side of Eq. 4 is proportional to the potential of the active material as written in the next equation.

$$
E\left(\operatorname{Li}_{y} \mathrm{M}_{2}\right)=-\frac{1}{F} \lim _{\Delta x \rightarrow 0} \frac{G\left(\operatorname{Li}_{y+\Delta x} \mathrm{M}_{2}\right)-G\left(\mathrm{Li}_{y} \mathrm{M}_{2}\right)}{\Delta x}
$$

Therefore, with decreasing the electrode potential ( $E(y)$ in Eq. 5), $\Delta G$ increases, meaning the equilibrium of Eq. 3 shifts toward left and vacancy in the material $1\left(\mathrm{Li}_{x} \mathrm{M}_{1}\right)$ decreases. On the other hand, when $E(y)$ is increased, $\Delta G$ decreases and vacancy in the material 1 increases.

$\mathrm{Li}_{2} \mathrm{SiO}_{3}-\mathrm{LiTiO}_{2}$ nano-composite.- To confirm the above model, $\mathrm{Li}^{+}$doped $\mathrm{TiO}_{2}\left(\mathrm{Li}_{\delta} \mathrm{TiO}_{2}\right.$, LTO $)$ was used as an active material, which shows lower electrode potential than $\mathrm{TiO}_{2}$. In this study, nano LTO with $\delta=0.01$ and $E=2.7 \mathrm{~V}$ vs. $\mathrm{Li} / \mathrm{Li}^{+}$was prepared and mixed with nano LSO with a volume fraction of nano LTO of 0.4. For LSO-LTO, it is expected that less $\mathrm{Li}^{+}$would be attracted to the interface due to the lower electrode potential, according to Eq. 5. In the Nyquist plot of LSO-LTO (Fig. 3c), a semi-circle and a straight line appeared, indicating the electronic conduction was negligible. Figure 6 shows that the conductivity of LSO-LTO decreased to $1 / 20$ of that of the 

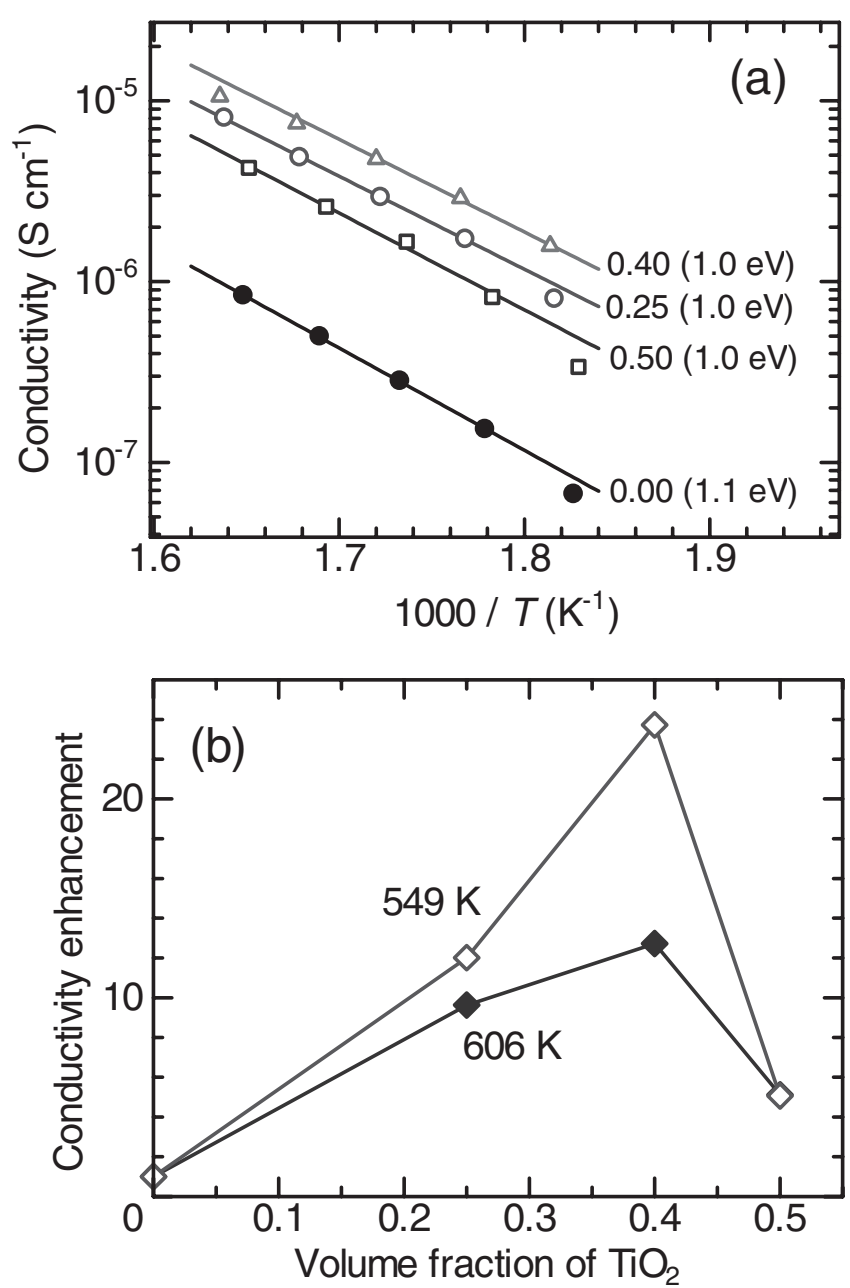

Figure 4. (a) $\mathrm{Li}^{+}$conductivities and their activation energy of nano-LSO and nano-composites of LSO-TO with various volume fraction of $\mathrm{TiO}_{2}$. (b) Composition dependence of $\mathrm{Li}^{+}$conductivity of LSO-TO. (a) LSO-LTO $(2.7$ V)

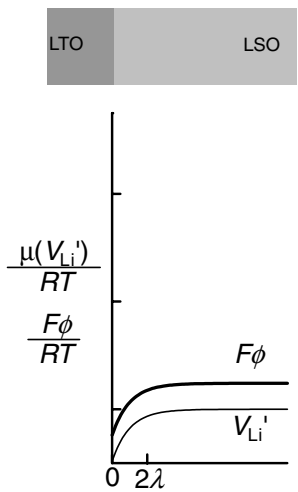

(b) LSO-TO (3.3 V)

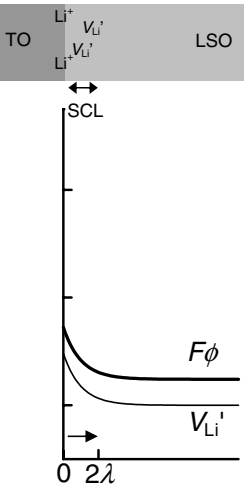

(c) LSO-FPO (3.5 V)

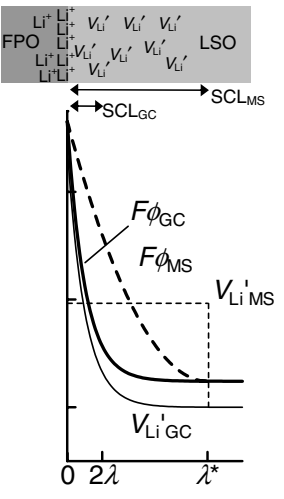

Length from the interface inside $\mathrm{Li}_{2} \mathrm{SiO}_{3}$

Figure 5. Schematic vacancy and potential profiles at the interfaces of LSOside for the composites (a) LSO-LTO $(\mathrm{OCP}=2.7 \mathrm{~V})$, (b) LSO-TO (OCP $=3.3 \mathrm{~V})$, and $(\mathrm{c}) \mathrm{LSO}-\mathrm{FPO}(\mathrm{OCP}=3.5 \mathrm{~V})$. Solid bold line: potential $(\varphi)$, solid line: density of chemical potential of lithium vacancy $\left(\left[V_{\mathrm{Li}^{\prime}}{ }^{\prime}\right]\right)$. For LSO-FPO (c), profiles for Mott-Schottky distribution are shown with dashed lines.

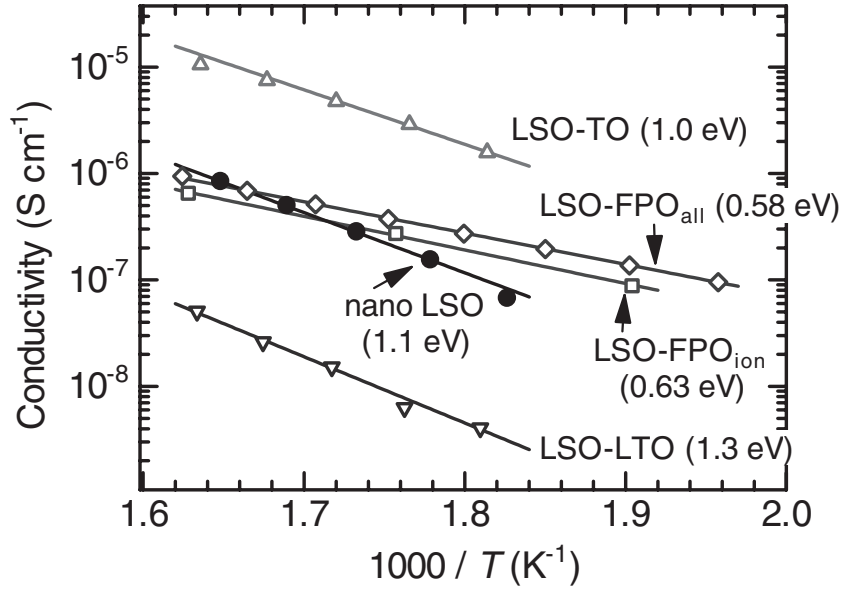

Figure 6. $\mathrm{Li}^{+}$conductivities and their activation energy of nano-LSO, nanocomposites of LSO-TO, LSO-LTO and LSO-FPO with a volume fraction of active materials of 0.4 .

pristine nano LSO with almost the same activation energy. In addition, crystal structure of nano LSO and nano LTO in the composite was the same as those of the pristine ones. This result is well explained by the above model. That is, the conductivity decreases because LTO behaves as just inert phase in the composite or LTO may behave as $\mathrm{Li}^{+}$donor to LSO, which decreases $V_{\mathrm{Li}}{ }^{\prime}$ in LSO and decreases $\sigma_{\mathrm{Li}}$ of LSO (Fig. 5a).

$\mathrm{Li}_{2} \mathrm{SiO}_{3}-\mathrm{FePO}_{4}$ nano-composite.- To study composites with higher electrode potential, $\mathrm{FePO}_{4}$ (FPO) with a potential of $3.5 \mathrm{~V}$ vs. $\mathrm{Li} / \mathrm{Li}^{+}$was used as an active material, because valence of $\mathrm{Ti}$ in $\mathrm{TiO}_{2}$ is +4 and $\mathrm{TiO}_{2}$ cannot be further oxidized and higher potential than $3.3 \mathrm{~V}$ vs. $\mathrm{Li} / \mathrm{Li}^{+}$cannot be reached with $\mathrm{TiO}_{2}$. For LSO-FPO, according to Eq. 3, it is expected that more $\mathrm{Li}$ ions are attracted to the interface due to the higher electrode potential. For the composite of LSO-FPO, Fig. 3d indicated that the Nyquist plot converged at a point on the real axis for lower frequency limit, meaning electronic conduction in the composite was not negligible. Therefore, $\sigma_{\mathrm{e}}$ of LSO-FPO was obtained from dc polarization. As shown in Fig. 7, the transient

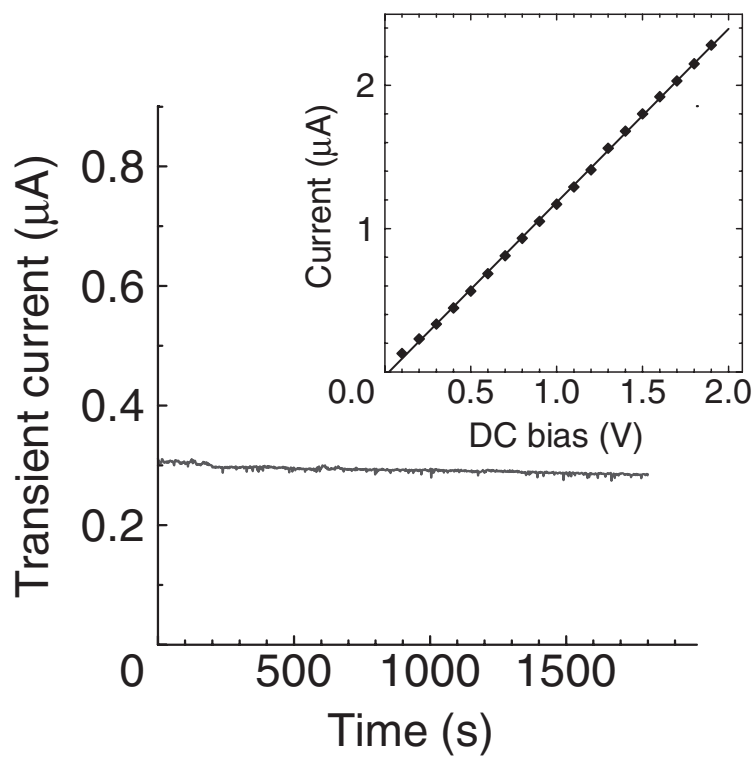

Figure 7. Transient curve on a dc bias of $0.2 \mathrm{~V}$ for $\operatorname{LSO}-\mathrm{FPO}(0.4)$ at $350^{\circ} \mathrm{C}$. The inset shows the bias dependence of transient current. 

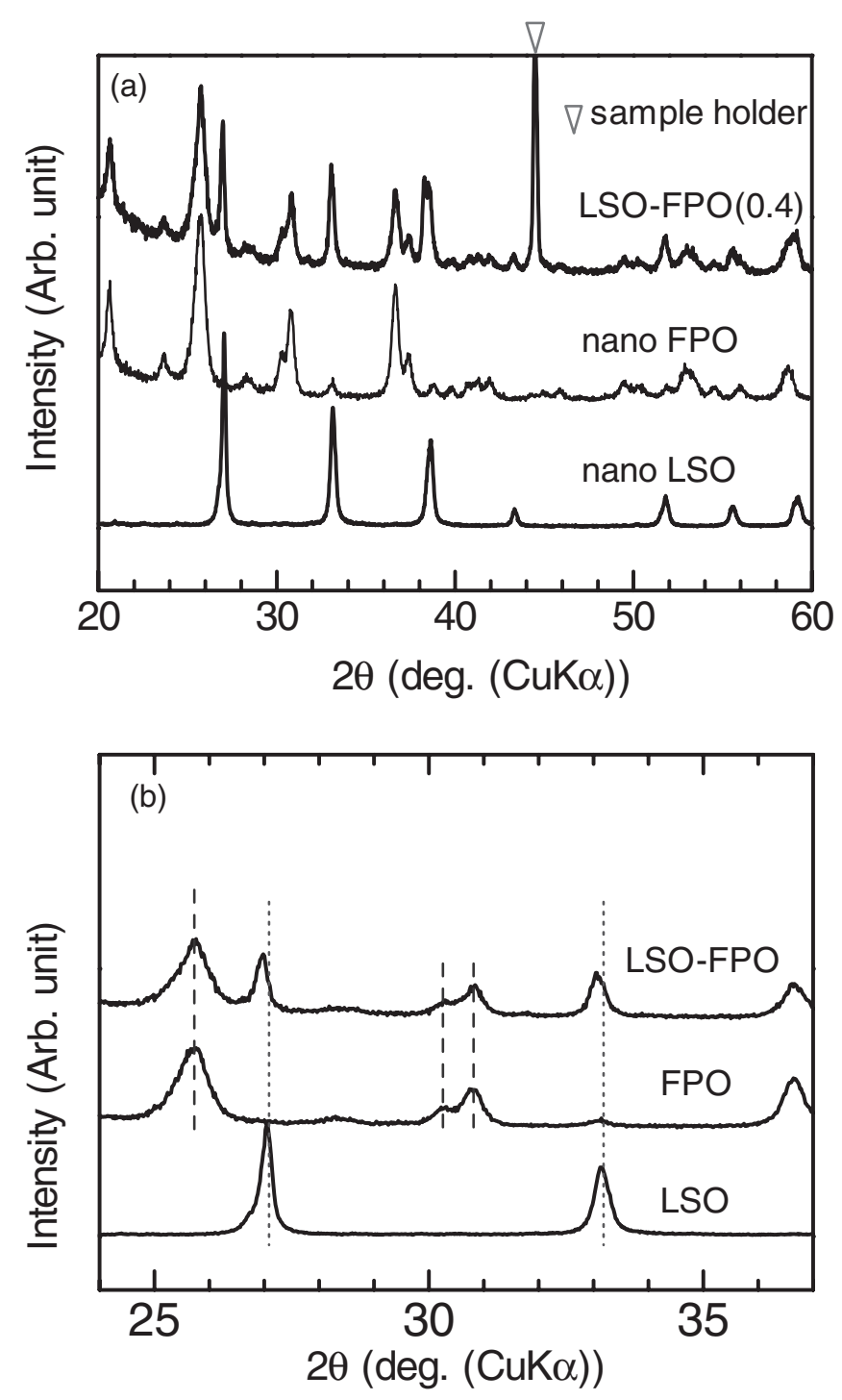

Figure 8. (a) XRD profiles of nano-LSO and LSO-FPO $(\varphi=0.4)$ and (b) their enlarged profiles.

current was almost stable for $30 \mathrm{~min}$. and was linearly increased with applied dc bias (see inset of Fig. 7). $\sigma_{\mathrm{e}}$ was estimated from the slope by using Ohm's law. $\sigma_{\mathrm{Li}+}$, which was estimated from ac impedance and dc polarization, was slightly increased at lower temperatures, in comparison to nano LSO (Fig. 6). It should be noted that the particle size of nano FPO was about $800 \mathrm{~nm}$ and much larger than nano TO and nano LTO $(11 \mathrm{~nm})$, and it is impossible to compare LSO-FPO with other composites. Interestingly, the activation energy of LSO-FPO composite was smaller than that of the pristine nano LSO. This indicates the change in the ion conduction mechanism and/or the change in the structure of LSO. XRD measurement didn't show the existence of any impurity phases for the LSO-FPO composite as shown in Fig. 8a. However, diffraction peaks related to LSO in the composite appeared at lower angles compared to pristine nano LSO, while those of nano FPO didn't shift (Fig. 8b). This result indicates that the lattice expansion occurred for nano LSO in the composite. The calculated lattice parameters of LSO in the composite was larger than that of the pristine nano LSO $(+1.3 \%$ in cell volume), but standard deviations of those values for the composite were large and it was difficult to distinctly demonstrate the lattice expansion. In ${ }^{7} \mathrm{Li}$ MAS-NMR spectra of the pristine LSO and LSO-FPO, no change in chemical shift and peak profile was observed (Fig. 9), meaning the local envi-

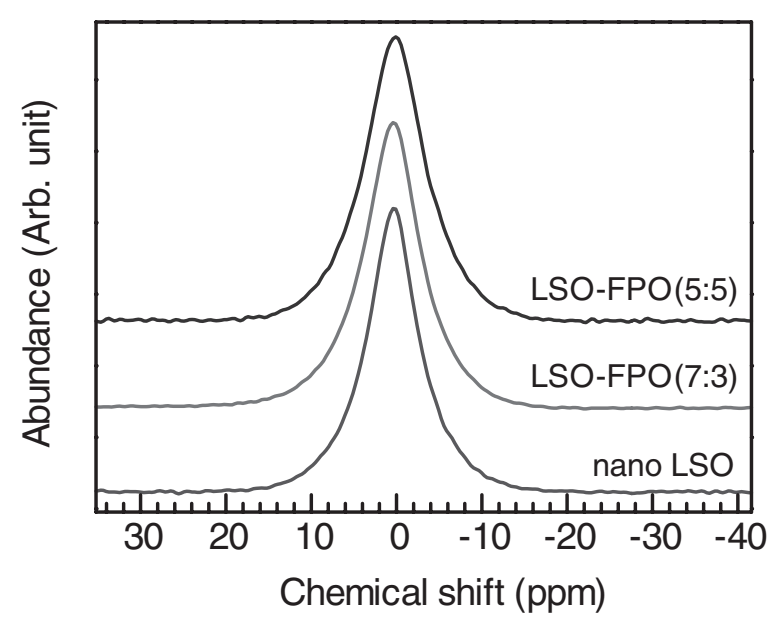

Figure 9. ${ }^{7} \mathrm{Li}$ MAS-NMR spectra of nano LSO and nano-composites of LSO-FPO with volume fraction of FPO of $30 \%$ and $50 \%$.

ronment of lithium ions in LSO were the same for both specimens, and the NMR spectra support the XRD result. Of course, the possibility of impurity phases beyond the sensitivity of XRD and NMR should be carefully considered. When the sensitivity of the measurements is supposed to be less than $1 / 50$ (based on the $\mathrm{S} / \mathrm{N}$ rate of the profiles) and the LSO particles are all spherical and $50 \mathrm{~nm}$ in diameter, thickness of undetectable phase would be ca. $0.2 \mathrm{~nm}$, i.e. one atomic layer on the LSO surface. This value is too thin to cause the drastic change in the ionic conduction. Therefore, it is concluded that extra phases were negligible on the interface of the LSO-FPO composite.

For the $\mathrm{Li}^{+}$conduction in LSO-FPO, two plausible mechanisms are proposed (Fig. 5c). The first model is that lithium ions in LSO are strongly attracted on the surface of FPO because the energy gain of $\mathrm{Li}$ transfer to FPO ( $\Delta G$ in Eq. 4) is large. This causes many lithium ion vacancies $\left(V_{\mathrm{Li}}{ }^{\prime}\right)$ in the LSO. While a lot of $V_{\mathrm{Li}}{ }^{\prime}$ enhance the ionic conductivity as explained by the space charge layer model, they also cause the lattice expansion, because $V_{\mathrm{Li}}{ }^{\prime}$ have negative relative charge in the crystal and they repulse each other. The expanded lattice results in wider bottle-neck on the $\mathrm{Li}^{+}$conduction and reduces the potential barrier on the $V_{\mathrm{Li}}{ }^{\prime}\left(\right.$ or $\left.\mathrm{Li}^{+}\right)$migration. The other plausible mechanism would be the $\mathrm{Li}^{+}$conduction in FPO. That is, a few lithium ions were inserted from LSO into FPO on their contact interfaces and conduct charges in FPO. This is supported by the fact that the observed activation energy of $0.63 \mathrm{eV}$ is close to that for $\mathrm{LiFePO}_{4}, 0.55-0.59 \mathrm{eV}^{30}$ This local reaction between LSO and FPO is not surprising, although LSO is electrochemically stable at this potential of $3.5 \mathrm{~V}$ vs. $\mathrm{Li} / \mathrm{Li}^{+}$. This kind of lithium insertion from electrolytes to active materials is confirmed by simulation. At an interface of $\mathrm{V}_{2} \mathrm{O}_{5}$ and $\mathrm{Li}_{2} \mathrm{SiO}_{3}$ glass, ${ }^{31}$ small amounts of $\mathrm{Li}^{+}$were inserted into $\mathrm{V}_{2} \mathrm{O}_{5}$ without the presence of an electric field.

We shall discuss defects profiles at the interfaces in detail. For the SCL model, two defects profiles are proposed: Gouy-Chapman (GC) profile and Mott-Schottky (MS) profile. ${ }^{29}$ For the GC case, defects are distributed on the basis of the Poisson-Boltzmann distribution in which electrochemical potential of all species is constant, and the SCL thickness $(\sim 2 \lambda)$ is independent of surface potential as mentioned earlier. On the other hand, for the MS profile, the charge concentration is supposed to be constant in the SCL. In this case, the SCL thickness $\left(\lambda^{*}\right)$ depends on the surface potential as follows:

$$
\lambda^{*}=\sqrt{\frac{2 \varepsilon_{\mathrm{r}} \varepsilon_{0}}{z F c_{\infty}}\left(\phi_{\infty}-\phi_{0}\right)}
$$


where $\phi_{\infty}$ and $\phi_{0}$ are potential in bulk and at the interface, respectively. Equation 6 indicates that the MS-type SCL can be thicker than the GC-type SCL. For LSO-FPO, the MS model may be applied due to the high surface potential (see dashed line in Fig. 5c). If such high surface potential is applied to GC distribution, the calculated defects concentration is higher than the concentration of all Li ions in LSO. In addition, the increase in the defects decreases the lattice energy, which suppresses formation of defects. Therefore, the concentration of defects is supposed to be saturated at a certain value and the MS type distribution is applied. The very thick depletion region $(\sim 1 \mu \mathrm{m})$ at the interface observed by electron holography may be also explained with the MS-like model. ${ }^{24}$

For more precise description of the interfacial phenomenon in the LSO-FPO system, further detailed analyzes with well defined interfaces are required. For example, the particle size of FPO $(\sim 800 \mathrm{~nm})$ was much larger than that of LSO $(\sim 50 \mathrm{~nm})$, meaning that not all LSO particles were in contact with FPO particles. And the surface sensitive measurements would be helpful to get information on the interfaces.

\section{Conclusions}

In summary, at interfaces of solid electrolytes and active materials, lithium-ion transfer across the interfaces occurs, which depends on the potential of the active materials. The $\mathrm{Li}^{+}$transfer causes change in the ionic conductivity at the interface and, in some cases, changes in the crystal structure. LSO that was used in this study is a poor ionic conductor and may not be used in real all solid state batteries. However, the $\mathrm{Li}^{+}$transfer would be more critical for batteries with high $\mathrm{Li}^{+}$ conducting solid electrolytes, because the main charge carriers of them are not $V_{\mathrm{Li}}{ }^{\prime}$ but $\mathrm{Li}^{+}$. The $\mathrm{Li}^{+}$transfer from such solid electrolytes to positive electrodes with high electrode potential leads depletion of the charge carriers in the solid electrolytes at the interface and thus increase in the interfacial resistance.

\section{Acknowledgments}

This work was financially supported by grant-in-Aid for Scientific Research on Priority Areas "New Frontier of Hetero-Interface Modification for High Temperature Applications Based on Nanoionics Principles" (439), the Ministry of Education, Culture, Sports, Science \& Technology (MEXT), Japan, as well as by Tokuyama Science Foundation. K. Ideta of Kyushu University is acknowledged for her measurements of ${ }^{7} \mathrm{Li}$ MAS-NMR.

\section{References}

1. P. G. Bruce, Chem. Comm., 19, 1817 (1997)

2. C. Fellner and J. Newman, J. Power Sources, 85, 229 (2000).

3. I. Moriguchi, R. Hidaka, H. Yamada, T. Kudo, H. Murakami, and N. Nakashima, Adv. Mater., 18, 69 (2006).

4. H. Yamada, K. Tagawa, M. Komatsu, I. Moriguchi, and T. Kudo, J. Phys. Chem. C, 111, 8397 (2007).

5. P. G. Bruce, B Scrosati, and J.-M. Tarascon, Angew. Chem. Int. Ed., 47, 2930 (2008).

6. H. Yamada, Y. Watanabe, I. Moriguchi, and T. Kudo, Solid State Ionics, 179, 1706 (2008).

7. K. M. Abraham, Electrochim. Acta, 38, 1233 (1993).

8. K. Takada, T. Inada, A. Kajiyama, M. Kouguchi, H. Sasaki, S. Kondo, Y. Michiue, S. Nakano, M. Tabuchi, and M. Watanabe, Solid State Ionics, 172, 25 (2004).

9. J. B. Bates, N. J. Dudney, B. Neudecker, A. Ueda, and C. D. Evans, Solid State Ionics, 135, 33 (2000).

10. D. Aurbach, A. Zaban, A. Schechter, Y. Ein-Eli, E. Zinigrad, and B. Markovsky, J. Electrochem. Soc., 142, 2873 (1995).

11. H. Aono, E. Sugimoto, Y. Sadaoka, N. Imanaka, and G. Adachi, Chem. Lett., 19, 331 (1990).

12. Y. Inaguma, C. Liquan, M. Itoh, T. Makamura, T. Uchida, H. Ikuta, and M. Wakihara, Solid State Comm., 86, 689 (1993).

13. R. Kanno and M. Murayama, J. Electrochem. Soc., 148, A742 (2001).

14. M. Tatsumisago and A. Hayashi, in Solid State Ionics for Batteries, T. Minami, M. Tatsumisago, C. Iwakura, S. Kohjiya, and I. Tanaka, Editor, Ch. 3.2, Springer, Tokyo, (2005).

15. R. Murugan, V. Thangadurai, and W. Weppner, Angew. Chem. Int. Ed., 46, 7778 (2007).

16. P. Knauth, Solid State Ionics, 180, 911 (2009).

17. N. Kamaya, K. Homma, Y. Yamakawa, M. Hirayama, R. Kanno, M. Yonemura, T. Kamiyama, Y. Kato, S. Hama, K. Kawamoto, and A. Mitsui, Nature Mater, 10, 682 (2011).

18. N. Ohta, K. Takada, L. Zhang, R. Ma, M. Osada, and T. Sasaki, Adv. Mater., 18, 2226 (2006).

19. N. Ohta, K. Takada, I. Sakaguchi, L. Zhang, R. Ma, K. Fukuda, M. Osada, and T. Sasaki, Electrochem. Commun., 9, 1486 (2007).

20. A. Sakuda, H. Kitaura, A. Hayashi, K. Tadanaga, and M. Tatsumisago, Electrochem. Solid-State Lett., 11, A1 (2007).

21. A. Sakuda, A. Hayashi, and M. Tatsumisago, Chem. Mater, 22, 949 (2010)

22. T. Okumura, T. Nakatsutsumi, T. Ina, Y. Orikasa, H. Arai, T. Fukutsuka, Y. Iriyama, T. Uruga, H. Tanida, Y. Uchimoto, and Z. Ogumi, J. Mater. Chem., 21, 10051 (2011).

23. M. Landstorfer, S. Funken, and T. Jacob, Phys. Chem. Chem. Phys., 13, 12817 (2011).

24. K. Yamamoto, Y. Iriyama, T. Asaka, T. Hirayama, H. Fujita, C. A. J. Fisher, K. Nonaka, Y. Sugita, and Z. Ogumi, Angew. Chem. Int. Ed., 49, 4414 (2010).

25. H. Yamada, I. Moriguchi, and T. Kudo, Solid State Ionics, 176, 945 (2005).

26. H. Yamada, A. J. Bhattacharyya, and J. Maier, Adv. Funct. Mater., 16, 525 (2006).

27. A. Yamada, H. Koizumi, N. Sonoyama, and R. Kanno, Electrochem. Solid-State Lett., 8, A409 (2005)

28. J. Maier, J. Phys. Chem. Solids, 46, 309 (1985)

29. X. Guo, I. Matei, J. Jamnik, J.-S. Lee, and J. Maier, Phys. Rev. B, 76, 125429 (2007).

30. R. Amin, P. Balaya, and J. Maier, Electrochem. Solid-State Lett., 10, A13 (2007).

31. M. E. Garcia, E. Webb III, and S. H. Garofalini, J. Electrochem. Soc., 145, 2155 (1998). 